\title{
Anterior Auricular Vein
}

National Cancer Institute

\section{Source}

National Cancer Institute. Anterior Auricular Vein. NCI Thesaurus. Code C53027.

A vein that drains the auricle and acoustic meatus of the external ear. 